\title{
Christian Rock Concerts as a Meeting between Religion and Popular Culture
}

\section{Introduction}

Different forms of artistic expression play a vital role in religious practices of the most diverse traditions. One very important such expression is music. This paper deals with a contemporary form of religious music, Christian rock. Rock or popular music has been used within Christianity as a means for evangelization and worship since the end of the 1960s. ${ }^{1}$

The genre of "contemporary Christian music", or Christian rock, stands by definition with one foot in established institutional (in practicality often evangelical) Christianity, and the other in the commercial rock music industry. The subject of this paper is to study how this intermediate position is manifested and negotiated in Christian rock concerts. Such a performance of Christian rock music is here assumed to be both a rock concert and a religious service. The paper will examine how this duality is expressed in practices at Christian rock concerts.

The research context of the study is, on the one hand, the sociology of religion, and on the other, the small but growing field of the study of religion and popular culture. The sociology of religion discusses the role and position of religion in contemporary society and culture. The duality of Christian rock and Christian rock concerts, being part of both a traditional religion and a modern medium and business, is understood here as a concrete example of the relation of religion to modern society.

The study of the relations between religion and popular culture seems to have been a latent field within research on religion at least since the 1970s, when the possibility of the research topic was suggested in a pioneer volume by John Nelson (1976). During the last few years, a number of anthologies attempting to map the field have been published (Forbes and Mahan 2000; Mazur and McCarthy 2001; Stout and Buddenbaum 2001). The studies in these anthologies could be roughly divided into two cate-

1 Two books looking at the history of Christian rock are Joseph 1999 and Thompson 2000. 
gories, one concerning religion in popular culture - religious themes, forms and functions within "secular" popular culture - and the other dealing with popular culture in religion - the use of popular cultural expressions within a particular religious tradition. This paper belongs to the second category, but it is still important to remember that the study of religion and popular culture does not only deal with explicitly for example Christian (or Satanist) pop culture.

Even if there is an emerging field of study of relations between religion and popular culture, the field is still very much in a stage where there are very few established theories, methodologies, research topics, etc. There are attempts particularly at establishing theoretically informed topics - one well worth mentioning is Colleen McDannell's (1995) fascinating book on "material Christianity" - but Christian rock concerts is not such a topic. This paper is therefore by necessity of an exploratory nature. It is an attempt at suggesting some directions for research by sketching some methodological points and applying them to a few examples.

The paper is included in a volume dedicated to the study of rituals. The significance of this concept here is that a rock concert can be seen as a ritual, for example, because it happens in a closed time and space, and involves a number of ritualized activities such as applause, solos, encores, etc. Indeed, one good example of the study of religion in popular culture is the discussion of rock concerts as religious rituals (Hämeri 1993; Weinstein 1995). A Christian rock concert can also be seen as a religious ritual in a narrower sense, by reason of its drawing on ritual practices of Christianity, notably prayer, sermons and - in various degrees of similarity - the singing of hymns. My approach to Christian rock concerts (and therefore to rituals in general) is here - by inspiration from semiotics or (post)structuralism to view and discuss them as texts.

The paper deals with Christian rock, and the following section discusses possible definitions of this concept. The paper then goes on to discuss the analysis of Christian rock concerts as texts. A concert video with the American Christian rock group dc Talk, as well as some other video material, is then explored.

\section{Defining Christian rock}

The distinction between "secular" popular culture and "religious" culture is of course problematic in many ways. In a larger perspective, which I will not address at any greater length here, the problems relate to the definitions of "religion", "culture" and "popular culture". In a more direct relation to the topic of the paper, the problems involved in drawing a line between 
secular and religious popular culture are reflected in the matter of defining "Christian rock". 2

Two different definitions of Christian rock have been hinted at in the previous passages. One definition, the one closest to a literal understanding, is that Christian rock is rock music with a Christian content. The other less obvious, but sociologically more relevant, definition is that Christian rock is rock music that is produced and consumed within institutional Christianity. These two definitions will be discussed further in the following passages. ${ }^{3}$ The discussion here serves mainly as an outline for a premise of the analysis of Christian rock concerts, but may also provide a brief general introduction to the world of Christian rock music.

There are many examples of rock music with a religious content, with various references to religions of Indian origin in music of the hippie era and the employment of Satanist material in some hard rock or metal genres being two of the best known examples. References to Christianity, ranging from the use of Christian texts such as the Kyrie or Ave Maria as lyrics in rock songs, to Christian symbols in music videos, are also fairly common. Sometimes these usages may be intended as ironic or even provocative, but sometimes they seem to be more earnest - although it is usually impossible to know merely by exploring the work in question without considering its context. The concept of "Christian rock" does not therefore include all music that uses Christian material in lyrics, visual presentation or indeed in the music. AChristian content or message - whether sincere or ironic is not enough as a criterion for Christian rock, but the institutional context must also be taken into account.

William D. Romanowski (2000) discusses the Christian music industry. He sees Christian rock as music produced, distributed and consumed within institutional Christianity. Christian rock is primarily marketed to young evangelical Christians, as a Christian alternative to secular rock. It is produced and distributed as a separate genre - or in radio terms, a format with particular Christian rock groups whose records are released by Christian record companies and listed on Christian top lists, who play at Christian rock festivals, who are reviewed and interviewed in Christian music magazines and sometimes even receive Christian music awards. ${ }^{4}$ It is of

2 Another term often used is "contemporary Christan music", abbreviated CCM. I prefer the term Christian rock, but see the two terms as equivalent.

3 The discussion here focuses on the first part of the term "Christian rock", and no further discussion of the definition of "rock" is pursued. A broad everyday definition is assumed, equating rock more or less with "popular music".

4 One of the largest Christian record companies is Word (www.wordonline.com), while others are listed on www.gospelmusic.org/links. The major Christian music magazine is called CCM (www.ccmcom.com). www.doveawards.com is the website of the organsiation that bestows the most prestigious Christian music awards, the "Dove awards". The largest Nordic Christian rock festival is arranged in Turku, and arranged 
course still important to note that even if Christian rock can be seen as a particular genre of popular music, the boundaries are never exactly clear, and an important topic in the Christian music press concerns these boundaries (see Häger 2001 for more on this issue).

The label "Christian", as used within the genre of Christian rock (or even the term "gospel"), already indicates that there is a strong connection between the music and the particular religious tradition, Christianity, and the carriers of this tradition, the churches or institutional Christianity. But I will still discuss briefly here the forms that this connection takes. On the one hand, it is possible to see the Christian rock industry as a "parachurch" type phenomenon, (evangelical) Christianity loosely organized in noncongregational forms, in this case for example as business corporations. On the other hand, the music is marketed to, and consumed by, churchgoing young people, Christian rock festivals are organized by Christian churches and movements, and there are churches which feature their "own" rock bands. ${ }^{5}$ A recurring topic in many interviews with Christian artists in the Christian music press (cf. Häger 2001 for a closer study) is the desire to sell records beyond the Christian bookstores and to play in other venues than churches. This repeated ambition to reach outside the churches shows that a strong connection to established Christianity is the rule in Christian rock.

A thorough discussion of the phenomenon of "Christian rock" is far beyond the scope of this paper. ${ }^{6}$ The brief comments here only serve to establish the idea that "Christian rock" or "contemporary Christian music" is a separate genre of music, and part of a Christian subculture devoted to this music, and to show that one, but only one, characteristic of this type of

by one of the largest evangelical revival movements in Finland (www.sley.fi/mn). (All these webpages accessed on 3.9.2002.) An Internet-based Christian rock station may be found on www.christianrock. net (26.9.2002). An example of a Christian rock chart (based on radioplay) can be found on www.jamsline.com/chartac.htm (16.9.2002). The link collection on the same site (www.jamsline.com/koollink.htm; 16.9.2002) gives an idea of the scope of the genre.

5 Apart from the Finnish festival mentioned in the previous footnote, one of the most established Swedish Christian rock festivals, "Rock for Moc", is organized by the diocese of Västerås in cooperation with the youth organisation of the same diocese (www.rockformoc.com; 16.9.2002). The largest European Christian rock festival, Greenbelt, is organised in cooperation with several Christian organisations, some of which are ecumenical and some part of the Anglican communion (www.greenbelt. org.uk/ aboutus/partners/; 16.9.2002). On www.sley.fi/nuoriso/vsivu.php?page=bandi (16.9. 2002) there is information on the rock groups run by the Lutheran Evangelical Association in Finland. The group whose video is discussed below, dc Talk, "got it's start at [Moral Majority leader] Jerry Falwell's Liberty University" (Joseph 1999: 222).

6 For studies of Christian rock, see e.g. Howard and Streck (1999), who discuss Christian rock from the perspective of Niebuhr's (1951) Christ and Culture; and Romanowski (2000), who focuses on the music business. 
music is that it has a Christian content. The discussion here serves as a background for the definition of Christian rock used in this paper: Christian rock has a Christian content and is produced, distributed and consumed as a separate music genre within institutional Christianity.

The paper discusses Christian rock concerts, or concerts where Christian rock is performed. The definition of Christian rock is therefore part of the definition of the material studied. A working definition of Christian rock is also important for the analysis, since the aim of the analysis is not to "show" or "prove" that the concerts feature Christian rock, but this is rather a premise and prerequisite, and the analysis instead discusses how this "fact", that the concerts feature Christian rock, may show in the practices of the concerts.

The most important quality of Christian rock is clear already in the term itself: it is something that is Christian, and it is rock. John J. Thompson puts it:

Christian rock melds faith and culture. It is called Christian because of the message in the lyrics, or at least because of the faith backgrounds of the artists [...] It is full-on rock and roll [...] yet it is used for worship [and] evangelism. (Thompson 2000: 11.)

Jay R. How ard and John M. Streck (1999: 3) point out this duality in relation to Christian rock concerts by saying that people going to Christian rock concerts are looking for "a clear affirmation of their most fundamental beliefs wrapped in a package of rock and roll music and fun, fun, fun". This characteristic of Christian rock being Christian as well as rock, two things at the same time, is the starting point for the analysis of Christian rock concerts in this paper.

\section{The analysis of a concert as text}

The material for the study presented in this paper consists primarily of a few commercially distributed videos with Christian rock groups. The

7 The duality of Christian rock, and of the concerts, is also part of the self-understanding of at least some Christian musicians, and also problematised to some extent. On one of the videos I have looked at (Jerusalem 2000), the lead singer of the veteran Swedish Christian heavy metal group Jerusalem, Ulf Christiansson, in a speech at a concert (held in 1983) says that "there are very few rock concerts that one leaves with peace in the one's heart, very few", and then goes on to lead the concert crowd in an $a$ capella praise hymn. He seems to point out that there is a discrepancy between rock music and what he implicitly defines as one aim of a Christian divine service, receiving peace of heart, and therefore uses a completely different form (and apparantly as the end of the concert) to acheive this aim. 
reasons for this choice are first and foremost practical. Although I have personally attended a number of Christian rock concerts, and also have composed field diaries from a few of these, I have so far recorded my own video material. For a paper such as this, the reference to publicly available material can even have the advantage that an interested reader has a greater possibility to access the material when it is commercially distributed than if it only is stored in the researcher's archives.

The concert videos are viewed as texts, and analyzed with the help of the concepts of syntagm and paradigm (Barthes 1977a; Fiske 1990). ${ }^{8}$ The syntagm is the chain of signs that are used in a certain text, e.g. a sentence made up of words. The paradigm (or system, in Barthes' term) is the "series of associative fields" (Barthes 1977a: 71) of the signs that could have been used instead of a particular sign actually used in a syntagm. John Fiske (1990: 57) says that signs are combined into a syntagm and selected from a paradigm. The meaning of a sign is derived both from its opposition to the other signs in the syntagm, e.g. the other words in a sentence, and the opposition to the other signs in the paradigm, e.g. the different synonyms or antonyms of a particular word.

A video of a rock concert is of course a very complex text. The syntagm of this type of text has, in the term borrowed from Roland Barthes (1977b), three different structures: the music, the words and the picture. ${ }^{9}$ The paradigmatic dimension is even more complex. A paradigm is, as already mentioned, a group of signs from which the actually used sign is selected. I will here make use of Barthes' observation that a paradigm is not necessarily one homogenous group, but can be several different "associative fields" from which a particular sign in a syntagm can be drawn. The two major "associative fields" - or repertoires or discourses (which are the terms I prefer to use) - that are used in creating the syntagm of a Christian rock concerts are (somewhat crudely labeled) "Christianity" and "rock". Other repertoires are also used, but these two are by definition the most important ones. The task of the analysis is to see how these two repertoires are used.

These two repertoires per se can be seen as a paradigm, as mutually exclusive options to be actualized in a given sign. A sign could then either belong to the "Christian"repertoire or to the "rock" repertoire, and draw part of its meaning from the opposition between the repertoires (opposition here primarily understood as a structuralist term, although it could in

8 In the discussion of the material, I use the terms "concert" and "concert video" as equivalent. The materials used are the videos, but they are videos of concerts, and the points I want to make could in principle be applied just as well to live and not taped concerts (but in practice it is rather more convenient to be able to rewind the tape and watch it again).

9 An individual frame could also be analysed as a syntagm made up of a number of visual signs. 
the current context also be understood in an ideological sense). It is also relevant to view a text such as a Christian rock concert as a use of appropriation, of moving a sign from one repertoire to another, and particularly taking signs from rock and making them into part of Christianity. The whole genre of Christian rock can be seen from this perspective, as receiving its meaning from being recognizably similar to one particular discourse secular rock - but still not the same as this.

If one sees the concert syntagm as three different structures, image, music and words, another task for the analysis will be to observe which repertoires are used in which structures. If one part of the definition of Christian rock is that it has a Christian content or "message", then the textual structure should by definition be using a Christian repertoire. ${ }^{10}$ According to the same logic, the musical structure draws on the rock repertoire. The most open and ambivalent structure, the one that is not in any sense predefined as a vehicle for a certain repertoire, is the image, that can use both "rock" and "Christian" - and other - signs.

It is very important to stress that the meaning of a sign comes from its opposition to, or difference from, other signs both in the syntagmatic and the paradigmatic dimension. The same individual sign can take on completely different meanings depending on the context. This is a very important premise for the following discussion of Christian rock concert videos. It is a premise based on semiotics, but the same thoughts are expressed in a famous example mentioned by Clifford Geertz (1973: 6-7) in his discussion of "thick description". The rapid contracting of the eyelids in one eye, or blinking, can mean many different things depending on circumstances, and in order to be able to interpret such a gesture, to say whether it signifies e.g. that the blinker has got something in his or her eye or is making a "conspiratorial signal to a friend", one must take the context into consideration. The context for the signs studied here is a Christian rock concert, and many signs that are interpreted to mean one particular thing here - and notably seen to signify dependence on a Christian or a rock repertoire - would be interpreted otherwise in other contexts, e.g. in secular rock concerts or at football matches.

10 But most words in e.g. the English language, if individual words are defined as the syntagmatic unit to be analysed, can hardly be said to be particularly "Christian". This can be resolved in two ways. It can be said that the words that are important in the analysis, the words that carry the central meaning, are perhaps exactly the words that are recognizable as part of a religious or Christian vocabulary. Or the syntagmatic unit can be defined differently, as sentences or -in song lyrics - verses. In this paper, however, the analysis of the textual structure is secondary. The assumption that the lyrics, the words, are the most directly Christian part of Christian rock may on another level be argued a particularly Protestant notion, and I will not argue against this. 


\section{"Welcome to the Freak Show" - discussion of a concert video}

I have viewed a number of concert videos with different Christian rock groups, and have here elected to discuss only one of them (only briefly referring to others), mainly for reasons of space. It is the longest video in my material (72 minutes), and the only one with (almost) entirely live material. It is a video with one of the most successful Christian rock groups of the 1990s, the American group dc Talk (1997). The video is called "Welcome to the Freak Show".

The dc Talk video contains 12 songs taped during an American concert tour in 1997. It contains live concert material from several different concerts, but it is structured as if it were a single concert, with a section of calmer songs in the middle, and the group's biggest hit, "Jesus Freak", as the final song (and of course it is difficult for a video viewer to tell the difference between different evenings and venues of the tour, since it all looks rather the same). This is the only one of the tapes in my material that primarily contains live songs (with some short clips of documentary material on the group, which I exclude from my discussion), and I will not discuss the 72 minute video in its entirety, but give a general description and focus on some parts of it. I will first briefly comment on the music and then go on to discuss words and finally images.

dc Talk performs guitar-based rock with what I would describe as a grunge-type sound, mixed with rap and vocal harmonies. ${ }^{11}$ The importance of the vocals - perhaps in character for a Christian band, where the lyrics are central - is indicated by the fact that all three permanent members of the group - Michael Tait, Kevin Max and Toby McKeehan - are vocalists (with other musicians appearing on albums and tours but not being defined as band members) (see figure 1). A general impression of the concert video is that, for the most part, it is at first sight a very typical American so-called "alternative" rock band, hard music and driving guitars. As mentioned, there is a part of the set with calmer songs, where the band members actually sing sitting in cushioned chairs and surrounded by tables, lamps, etc. to give the stage the appearance of a living-room more than a rock stage. The songs in this part sound more like Christian "praise" songs, performed acoustically with very prominent vocal harmonies. This is perhaps particularly true of "In the Light" (written by the Christian musician Char-

11 A site (http:/ / ccmwhatisit.bizland.com; 19.9.2002) dedicated to among other things comparing Christian rock to "secular" counterparts to help visitors "Find Christian music to replace your secular music" (italics in original) states that dc Talk perform "Innovative vocalized pop/rock, sounds similar to U2, Oasis, Seal"; and another site with general information on Christian rock says that $\mathrm{dc}$ Talk "have mixed rock, rap and pop in previously unimaginable ways" (www.jamsline.com/b_dc_talk.htm; 19.9.2002). 
lie Peacock and one of the few cover songs on the tape), which would then be the best exception on the dc Talk tape to the previously assumed rule that the musical part of the syntagm draws on the rock repertoire.

\section{Words}

It was stated above, as part of the definition of Christian rock, that the structure of the syntagm to most clearly use a Christian repertoire would be the words, song lyrics and short speeches made by the band members between songs. I will here comment on the lyrics of three of the songs appearing on the dc Talk video, and on some of the speeches.

dc Talk's biggest hit is "Jesus Freak" (Joseph 1999: 223). ${ }^{12}$ It is a rock song with very prominent guitars and a catchy melody in the chorus. The main theme of the lyrics is conversion. The song begins:

Separated, I cut myself clean

From a past that comes back in my darkest of dreams

Been apprehended by a spiritual force

And a grace that replaced all the me l've divorced

The very first line contains three words that describe a conversion experience and its perceived result. The narrator has been and has become "separated", by "cutting" (not "moving" or "inching away"), from his ${ }^{13}$ past - and from the world - and has become "clean". The past is further described in the second line: it was a nightmare. The last two lines in the verse emphasize that the conversion was the work of someone or something outside the narrator, a "spiritual force" that has "apprehended" (not for example "approached") the narrator, and "a grace" that (as I understand the last words of the verse) filled out the holes in the person and made him whole. The word choices do not echo traditional Christianity, as perhaps particularly the term "spiritual force" can exemplify. Altogether, however, it should not be difficult to see that the verse contains elements of a classical conversion narrative.

The chorus is a reflection on the possible reactions from others regarding the new status following the conversion:

What will people think

When they hear that I'm a Jesus freak

What will people do when they find that it's true

12 The song lyrics can be found on www.ardent-enthusiast.com, and on the video (dc Talk 1997).

13 The singer is a man - as are all three members dc Talk - hence the pronoun. 


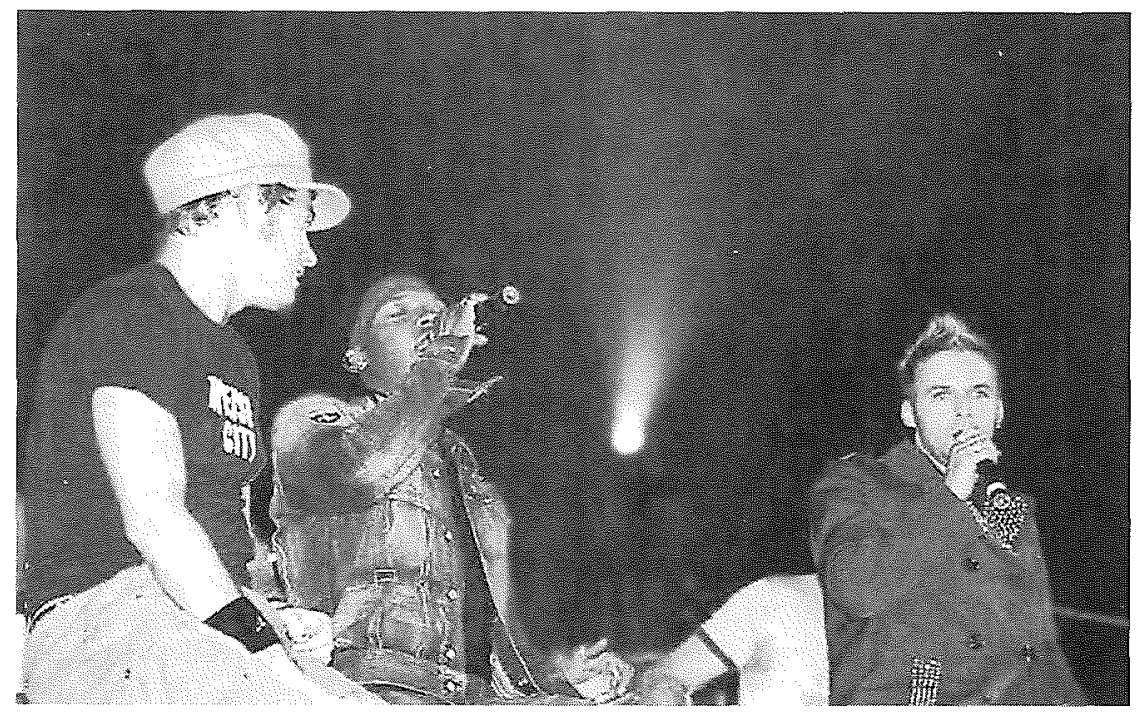

Figure 1. dc Talk in concert. From left to right: Toby McKeehan, Michael Tait and Kevin Max. Photo: Megan Reedy. All rights reserved, copyright 2002 Megan N. Reedy.

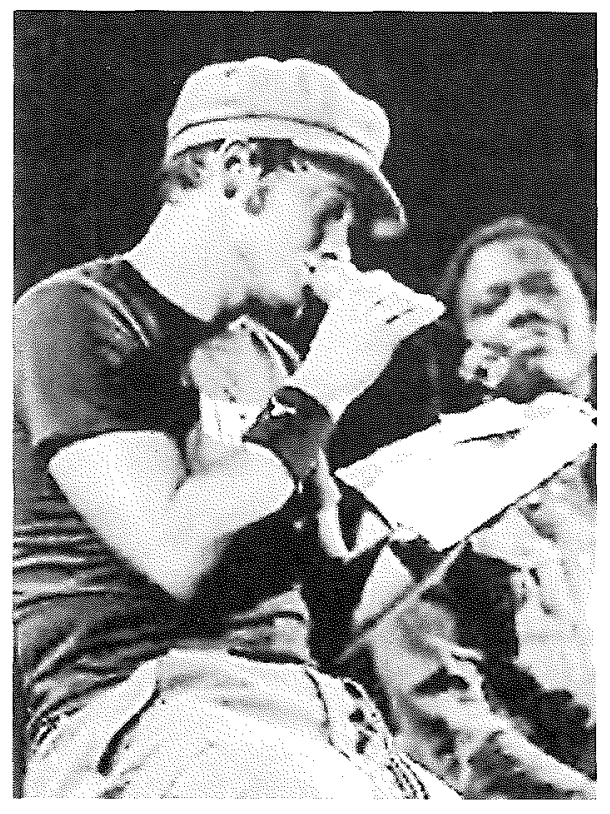

Figure 2. dc Talk's Toby McKeehan in concert reading from the Bible. Michael Tait in the background. Photo: Megan Reedy. All rights reserved, copyright 2002 Megan N. Reedy. 
I don't really care if they label me a Jesus freak

There ain't no disguising the truth

The chorus and the title of the song is an appropriation of an expression that could be taken as derisive, calling (a certain group of) Christians "Jesus freaks". The song turns this into a positive term, describing "the truth". dc Talk also seem to take the "freak" label as their own and even naming their concert tour "The Freak Show", a term also used in the video title. The song "Jesus Freak" is on the concert video introduced by Toby McKeehan with the phrase "we ain't nothing but a bunch of Jesus freaks". The band consider themselves part of a group that someone scornfully might call "Jesus freaks" and make this an important part of their identity.

Even if it can be said that the lyrics to "Jesus Freak" present a traditional evangelical view, they do so in a fairly untraditional way, in using innovative language and metaphors, beginning with the title of the song as discussed above. It would perhaps be possible to see this as an indication that the lyrics draw partly on a rock repertoire, that they are in some sense typical rock lyrics. The positive use of the word freak could be an example of this, if one sees rock as a "counter culture" that makes the inversion of the norm a central part of its message (Martin 1979). More generally speaking, another and different example of a use of the rock repertoire in the textual structure could be the parts of the lyrics that are rapped rather than sung.

If "Jesus Freak" is an example of innovative and "counter-cultural" lyrics, the above mentioned acoustically performed song "In the Light" can at least partly be used as example of a more traditional type of lyric. The words

Oh, Lord be my Light and be my salvation

Cause all I want is to be in the Light

in the chorus use a traditional form - prayer - and more traditional vocabulary than the lyrics of "Jesus Freak". Since the music of "Jesus Freak" is much more clearly rock (and perhaps the group's most typical grunge song), the two songs may be taken as an example of correspondence between music and lyrics.

Two of the members of dc Talk are white and one is African American. The group has an active anti-racist involvement in several ways and has founded an organization called "Erace" for this purpose (http: / / erace.com / about/history.shtml; 24.9.2002); and the organization is also promoted on the concert tape (after the concert material) (dc Talk 1997). One of the songs on the concert tape also takes up this topic. The song is called "Colored People", and is introduced on the concert video by one of the singers (off camera): 
[...] part of our beauty as human beings is found in our diversity. We happen to believe that we are all different shades and tones when it comes to our skin because God is a very creative artist, because aren't we all in fact "Colored people". (dc Talk 1997.)

The chorus of the song goes

We're colored people, and we live in a tainted place We're colored people, and they call us the human race We've got a history so full of mistakes

And we are colored people who depend on a Holy Grace

The spoken introduction to the song "Colored people" and this quote from the lyrics may serve as an example showing that the textual material from dc Talk is not entirely focused on classic evangelical issues - e.g. the need for personal salvation - but also on more political matters such as racial relations. It is, however, also important to note that this political issue is tackled partly through religious means, by saying that we are all different colours because this is how God made us, and that we all "depend on a Holy Grace".

There are a few other instances where one of the singers speaks, either shouting out a few short phrases within a song (see below for examples), or speaking between songs. As an introduction to "In the Light", McKeehan reads a verse from the Bible: "Anyone who says he is walking in the light but dislikes his fellow man is still in darkness, but whoever loves his fellow man will truly be walking in the light" (1. John 2:9-10) (see figure 2). He then continues to tell the audience that the band had been to a hospital earlier in the day to visit someone: "his name is Brian, you can keep him in your prayer". The concert video ends with a short sermon by McKeehan, with an invitation to the members of the audience to become Christians:

If you're here tonight who have become curious about this Jesus Christ that we're talking about [...] Ask him to come into your life and to walk with you. Find a Bible and read about the person of Jesus Christ, discover for yourself. You'vebeen a great crowd, thanks for making this tour welcome here. God bless you, peace, goodnight.

The spoken passages, with the appeal to the audience to pray for Brian, and the final invitation to "ask [Jesus] to come into your life", thus express very traditional elements of evangelical Christianity. And the duality of the situation is again expressed at the end of McKeehan's final speech, where he concludes by calling the audience "a great crowd". 


\section{Image}

It has been stated several times above that the music and text of Christian rock draws by definition on respective repertoires, so that the music is rock and the lyrics are Christian. In the brief comments on these two syntagmatic structures I have tried to show that it is possible that both of them may also draw on both a Christian and a rock repertoire. The third, visual, structure is however still presumed to be the most open and the least defined in advance in regard to how it draws on rock and Christianity. It is also the structure which seems most particular to the rock concerts: both music and lyrics are contained on albums, but the visual elements are relevant only at concerts (and in music videos). There therefore seem to be two reasons why the visual aspect is the most important in approaching a study of Christian rock concerts: it is the most open, and the one that most clearly sets concerts apart from listening to music on albums.

In the discussion of the visual elements, I will again draw on Roland Barthes (1977b: 15-31), who sketches a method for very detailed analysis of photographic images. I will only apply a few of Barthes' suggestions to the extent that I find them applicable and practical here. Barthes' point relies on the distinction between the denotative-presumably primary, given - meaning of a sign and its connotative - secondary - meaning; as well as on the assumption that we see photographic images as perfectly denotative, as something that shows things as they are and does not require interpretation. Barthes (1977b: 21-25) challenges this notion of photographic images as denotative and looks at different "procedures" (as he calls them) to create connotative meaning in the in principle denotative photograph (or film). I will discuss here the two procedures that most directly concern what is actually in front of the camera rather than photographic technique (such as trick photography, lighting, etc.). The two procedures are "poses" (in which I include gestures) and "objects".

The focus of the visual impression of a rock concert, or of a recording of such a concert, is the performing artist or group. One main reason for coming to a concert is to see the artists in real life - or, to use a word that strongly emphasizes the visual aspect, to see one's "idols". The audience also becomes part of the image, albeit in different ways on a video recording than in a live concert, when the rest of the audience most often merely disturbs the view of the artists. If one wants to look at the image structure of e.g. the concert video with dc Talk (1997) to see to what extent it draws on Christian, rock and other possible repertoires, the visual appearance of the artists becomes central and Barthes' concept of "pose" is one possible tool for studying this. A pose or gesture is according to Barthes (1977b) not immediate and denotative in the way we assume photographs to be, but it relies on a cultural code or knowledge of a cultural context for interpretation. 
Its meaning is, in other words, connotative (the example Barthes gives happens to be one with religious connotations: he mentions a photograph of John F. Kennedy where the latter puts his hands together and looks up in a praying pose). The same is to a greater extent true of objects that can give rise to certain associations - a book-case refers to intellectuals, in Barthes' example - or can function as symbols

The fundamental assumption of this paper is that a Christian rock concert is both Christian and rock, and the purpose here is to look at possible ways in which this duality may be expressed in the concerts, in both music, text and image. It is further assumed that duality does not imply equal weight: it does not require a certain substantial proportion of the syntagm from a certain repertoire to show that the text depends on a particular repertoire or discourse. A sign can be used to convey a large content, showing all of Molière "in a doctor's ruff", to borrow another example from Roland Barthes (1972: 127). This is here applied to the discussion of pose and object, where it is not assumed that the duality of Christian rock must be expressed by an equal amount of rock instruments and religious pictures on stage, for example, but rather that one orthodox icon - or correspondingly one Buddha statue - would be quite enough to indicate a reference to the respective religious traditions.

\section{Poses and gestures}

A rock concert is in many ways a very physical experience. Neither the artists nor the audience tend to sit or stand still to any greater extent, but rather move around more or less to the beat of the music. An important group of poses and gestures can then be grouped together as dancing or perhaps jumping to the music. This group of images I would interpret as part of the rock repertoire, as a way of showing that the occasion in question is a rock concert - as opposed to a classical concert, for example, or a Sunday morning service (acknowledging the fact that some of these also may include prominent physical experiences). A rather extreme example is the so called "stage diving", when somoene dives off the stage into the audience, which (hopefully) catches the person. This also occurs on the dc Talk video, where at least one of the singers (McKeehan) stage-dives.

The Finnish popular music researcher Sven-Erik Klinkmann (1999: 17079) points out the significance of gestures in the performance of popular music, giving as examples e.g. B. B. King's putting his finger in his ear and Elvis wagging his little finger. The use of such gestures may thus be seen as references to the rock repertoire, and in some examples in the dc Talk concert - particularly the "love sign" (see below) - as appropriations from a rock repertoire into a Christian discourse. 
There are, however, also a few gestures that could be interpreted as drawing on a Christian repertoire. The most obvious ones are a few instances when one of the singers (Max) crosses himself. There are also pictures of all three singers (at different times) kneeling as if to pray (a gesture used prominently on a concert video by the English group Delirious? [2000], not further discussed here), including a sequence where McKeehan kneels with arms and face upwards singing "won't you forgive me". There is another image of McKeehan holding his hands together and bowing his head (as if) in prayer. There are also, particularly during the quieter part of the set, shots of prayer-like gestures from the audience. During "In the Light", there are people in the front row of the audience stretching out their arms and closing their eyes, which is uncharacteristic behaviour at a rock concert, where one wants to see the performers, but a typical pose at some Christian meetings. Let me again point out that these gestures do not make the performance of dc Talk (or Delirious?) into a Christian rock concert, but are here interpreted as signs serving to remind the audience (whether concert or video) - who already are supposed to know that this is a Christian group playing - of precisely this fact.

To make the sign of the cross is not part of the ritual practices of the evangelical tradition to which dc Talk (and many other Christian rock artists) belong. One perhaps less easily recognizable gesture in more frequent use at the concerts on the video however is. The gesture involves stretching one (usually the right) arm straight up and pointing with the index finger (on an otherwise clenched hand) to the sky. This gesture has been called "one way" and was a symbol of the Charismatic movement and the Jesus movement in the 1970s, also used on stickers, T-shirts, etc. (cf. McDannell 1995: 25,253). The "one way" gesture is used repeatedly by both band members and audience on the dc Talk video, most notably at the end of the last song, where it is textually anchored by Toby McKeehan, who with his index finger pointing upwards repeatedly cries out "Jesus is the way, Jesus is the way", and finally completes with "and the truth and the life, no one comes to the Father but through him" (cf. John 14:6). The anchoring (Barthes 1977b: 39-41) of an image with text limits the possible interpretations and steers the reader in a certain direction, here in the direction of interpreting the index finger pointing upwards as a symbol of the Christian way.

I will comment on one more hand gesture, the most prominently featured one on the concert video, used by band members as well as audience. This is a raised hand with little finger, index finger and thumb extended. To illustrate the perhaps surprising significance of such seemingly trivial gestures, I will quote the American Christian anti-rock activist Jeff Godwin (1988), who reports from a visit to a concert by another famous American Christian rock group, Petra. Godwin says he saw two Petra members mak- 
ing the sign of "il cornuto" ("the horned", or also "the cuckold"), a fist with the little and index fingers extended, forming the hand to look like a head with two horns. This is a gesture very common in the heavy metal culture, not least at concerts. Godwin says of the Petra concert:

[Singer] John [Schlitt] lifted his hand straight up and made the Il Cornuto sign of allegiance to Satan! This is a bonafide symbol of satanism [...] This was NOT the sign language for "I love you" where the thumb also is openly extended. [...] I know what I saw and never in a million years did I expect to see such a thing at a "Christian" concert. (Godwin 1988: 307, 309.)

Godwin tells us that he wrote to the members of Petra to confront them on the matter, and they answered that they "may have used the 'love' symbol but could not remember specifically" (Godwin 1988: 309). In any case, it appears that Godwin - and Petra - are talking of the same gesture used at the dc Talk concert, something called the "love" sign, that is similar to, but also differs from, "il cornuto". ${ }^{14}$

The use of this so-called love sign, as well as Godwin's discussion of the Petra concert, may be seen as an illustration of some of the main points of this paper. The meaning of these three protruding fingers can be understood only by comparing and contrasting the sign to another sign, the gesture of the cornuto, which is similar but different. The difference between the two gestures further signifies the difference between the Christian and the rock repertoires. But the similarity - to the point of confusion - points out that this is not least a case of appropriation: a sign that is perceived as evil, portraying a head with horns, or - as Godwin (1988) claims - even signifying allegiance to Satan, is appropriated, slightly altered and used to signify something infinitely good, love.

\section{Objects}

When it comes to the objects visible on a rock stage, there usually are many things -instruments and technical equipment-clearly indicating that rock is what is going on here. This is certainly also true of the dc Talk concerts. Another type of object that is often used to signify "rock" is different forms of clothing. In the case of dc Talk, the clothes are of a "street" style, including the typical hip hop knitted cap. A special object that signifies popular music, but not especially rock music, is a mirror ball, most associated with

14 According to the American Sign Language Browser (http://commtechlab.msu. edu/sites/aslweb/ browser.htm; 30.9.2002), the sign for "love" is made so that "the hands hug something over the heart", while the "love" sign of dc Talk (and possibly Petra) simultaneously forms the sign language letters " $\mathrm{I}$ " and " $\mathrm{L}$ ", beginning the sentence "I love you". 
discotheques, reflecting its light on the stage during one song on the video.

As previously mentioned, during the quieter part of the concert the stage is decorated like a room, with couches, chairs, tables, lamps, candles, etc. This is decidedly the part of the concert with the greatest number of other objects than typical rock equipment. Unless one wants to point out that candles are part of the paraphernalia of some Christian services, it is rather clear that these objects do not refer to a particularly Christian repertoire (but perhaps rather to a bourgeois one). I find the most important aspect of the furniture to be the fact that the group members actually sit on it, and for a part of the concert refrain from the more typical rock concert behaviour of dancing to the music. The physical object with the clearest reference to Christianity to appear on the stage is a Bible (or New Testament) out of which McKeehan reads the passage from 1. John quoted above (figure 1).

One special feature of the dc Talk stage show as recorded on dc Talk (1997) is a big film screen at the back of the stage, with pictures illustrating the different songs. The song "Colored People", for example, is accompanied by pictures of people of different ethnicities. The song "Mind's Eye" is illustrated with several different images, of eyes, of a cyclone-like formation (the lyrics mentions hurricanes), etc. The theme of the song is believing without seeing:

Can you catch the wind?

See a breeze?

Its presence is revealed by

The leaves on a tree

An image of my faith in the unseen

In my mind's eye

I see your face

There are two images with references to the Christian sphere. There is a clip with the perhaps best known American evangelical preacher, Billy Graham. You can also hear him speaking: "Can you see God, have you ever seen him? I've never seen the wind, I've seen the effects of the wind", referring to John 3:7-9. ${ }^{15}$ Later there is a shot from a helicopter flying in over Rio de Janeiro and ending up with a picture of the world-famous large Christ statue, as the singers repeat the words "I believe, I believe". The pictures on the screen (perhaps representing what is seen "in my mind's eye") carry a certain weight in expressing a Christian message, or at least

15 The spoken words by Billy Graham are also included on the album version of the song (dc Talk 1995). 
giving certain associations to Christianity, but it still seems that they need the anchoring words of Billy Graham or dc Talk to more clearly refer to a Christian discourse.

One final example of objects on a Christian rock stage will be selected from another video, with the Swedish Christian heavy metal band Jerusalem (2000). The concert sequence in question was taped in 1983, and in a typical 80 s metal fashion, one song ends with a big smoke bomb going off behind the drummer. But just as the first smoke clears, there appears a big sign made up of a number of burning torches, which in large red capital letters spell out the word "Jesus". The torches burn down to the sound of distorted guitars (and there then follows a short speech by the group's lead singer as referred to in footnote 7). The combination of smoke bomb and heavy metal guitars on the one hand and the "Jesus"-sign on the other is in its almost naive fashion a clear illustration of the duality of Christian rock, and the fact that the reference to a Christian repertoire is verbal also serves as a reminder that the most important Christian aspect of Christian rock is expressed in words.

\section{Concluding remarks}

The purpose of this paper has been to examine how the dual character of Christian rock, being both Christian and rock, is expressed in the practices of Christian rock concerts. This has been done primarily through a discussion of the music, text and image of a concert video with the Christian rock group dc Talk. It has been the starting assumption of this study that dc Talk is a "Christian" rock group, communicating a Christian message on records, at concerts, etc., produced, distributed and consumed within an institutional Christian framework. The task has been to suggest how this may show in their concerts by discussing how the different aspects of the concerts draw on a rock or Christianity repertoire (or discourse) respectively. It was initially assumed that a Christian rock concert would be both a concert and a religious service. The assumption carries an important point, but it must still be emphasized strongly that the rock concert aspect is rather more easily recognizable in the material studied in this paper.

The study of religion and popular culture, and more specifically of Christian rock or of Christian rock concerts as rituals, is a far from established field. Partly because the field is very undeveloped, it is theoretically and methodologically rather insecure. This paper is therefore not an attempt to draw grand conclusions, but is more by way of an attempt to explore possibilities of interpretation and suggestions for further discussion of the relations between religion and popular culture. 


\section{References}

\section{Audiovisual sources}

dc Talk 1995: Jesus Freak. Forefront Records. [CD]

dc Talk 1997: Welcome to the Freak Show: dc Talk live in concert. Forefront Records.

[video]

Delirious? 2000: Pro-mod:e. Delirious? in 5d: global hypercolour. Furious? Records. [video]

Jerusalem 2000: Jerusalem music video. FRVD001 Fruit Songs. [video]

\section{Web pages}

http:/ / ccmwhatisit.bizland.com; 19.9.2002

http:/ / commtechlab.msu.edu/sites/aslweb/browser.htm; 30.9.2002

http://erace.com/about/history.shtml; 24.9.2002

www.ardent-enthusiast.com; 17.9.2002

www.ccmcom.com; 3.9.2002

www.christianrock.net; 26.9.2002

www.doveawards.com; 3.9.2002

www.gospelmusic.org/links; 3.9.2002

www.greenbelt.org.uk/aboutus/partners/; 16.9 .2002

wWw.jamsline.com/b_dc_talk.htm; 19.9.2002

www.jamsline.com/chartac.htm; 16.9.2002

www.jamsline.com/koollink.htm; 16.9.2002

www.rockformoc.com; 16.9.2002

www.sley.fi /mn; 3.9.2002

www.sley.fi/nuoriso/vsivu.php?page=bandi; 16.9 .2002

www.wordonline.com; 3.9.2002

\section{Printed sources}

Barthes, Roland

1972 Mythologies. London: Jonathan Cape.

1977a Elements of Semiology. New York: Hill and Wang.

1977b Image - Music - Text. Glasgow: Fontana.

Fiske, John

1990 Introduction to Communication Studies. London: Routledge.

Forbes, Bruce David, and Jeffrey H. Mahan (eds)

2000 Religion and Popular Culture in America. Berkeley: University of California Press.

Geertz, Clifford

1973 The Interpretation of Cultures. New York: Basic Books.

Godwin, Jeff

1988 Dancing with Demons: The Music's Real Master. Chino: Chick Publications.

Häger Andreas

2001 Religion, rock och pluralism. En religionssociologisk studie av kristen diskurs om rockmusik. Uppsala: Uppsala universitet.

\section{Hämeri, Heikki}

1993 Rock ' $\mathrm{n}$ ' ritual. Suomen Antropolog i 18 (1): 20-31. 
Howard, Jay R., and John M. Streck

1999 Apostles of Rock: The Splintered World of Contemporary Christian Music. Lexington: The University Press of Kentucky.

Joseph, Mark

1999 The Rock \& Roll Rebellion: Why people of faith abandoned rock music and why they are coming back. Nashville: Broadman \& Holman.

\section{Klinkmann, Sven-Erik}

1999 Elvis Presley: Den karnevalistiske kungen. Åbo: Åbo Akademi University Press.

Martin, Bernice

1979 The sacralization of disorder: Symbolism in rock music. Sociological Analysis 40 (2): 87-124.

Mazur, Eric Michael, and Kate McCarthy

2001 God in the Details: American religion in popular culture. New York: Routledge.

McDannell, Colleen

1995 Material Christianity. Religion and Popular Culture in America. New Haven: Yale University Press.

Nelson, John W.

1976 Your God Is Alive and Well and Appearing in Popular Culture. Philadelphia: Westminster Press.

Niebuhr, H. Richard

1951 Christ and Culture. New York: Harper \& Row.

Romanowski, William D.

2000 Evangelicals and popular music: The contemporary Christian music industry. In: B. D. Forbes and J. H. Mahan (eds.), Religion and Popular Culture in America; pp. 105-24. Berkeley: University of California Press.

Stout, Daniel A., and Judith M. Buddenbaum (eds.)

2001 Religion and Popular Culture: Studies on the interaction of worldviews. Ames: Iowa State University Press.

Thompson, John J.

2000 Raised by Wolves: The story of Christian rock \& roll. Toronto: ECW Press. Weinstein, Deena

1995 Rock music: Secularisation and its cancellation. International Sociology 10 (2): 185-95. 